\title{
Novel methodology for the extraction and identification of natural dyestuffs in historical textiles by HPLC-UV-Vis-ESI MS. Case study: chasubles from the Wawel Cathedral collection
}

\author{
Katarzyna Lech • Maciej Jarosz
}

Received: 1 September 2010 /Revised: 9 December 2010 / Accepted: 9 December 2010 /Published online: 28 December 2010

(C) The Author(s) 2010. This article is published with open access at Springerlink.com

\begin{abstract}
High-performance liquid chromatography coupled with spectrophotometric and electrospray mass spectrometric detection (HPLC-UV-Vis-ESI MS) was used for characterization of natural dyes present in historical art works. The gradient program was developed for identification of 29 colorants of various polarities. Dual detection system (UVVis and ESI MS) allowed differentiation of all compounds, even if they were not completely separated. This enabled examination of more color compounds over a substantially shorter time in comparison with previously recommended methods. Moreover, for extraction of colorants from historical textiles a two-step sequential procedure was proposed, excluding evaporation used in earlier procedures. The developed method was successfully applied to identification of indigotin, carminic, kermesic, flavokermesic, dcII, dcIV, $\mathrm{dcVII}$, and ellagic acids as well as luteolin, apigenin, and genistein in red, violet, and green fibers taken from three selected historical chasubles which belong to the collection of the Wawel Cathedral treasury (Cracow, Poland). Italian textiles from the fifteenth and sixteenth centuries, of which chasubles were made, were dyed with a limited number of dyestuffs, consistently used for all batches of fabrics. The obtained results also allowed confirmation of the structure of
\end{abstract}

Published in the special issue Focus on Analytical Science in Poland (VIIIth Polish Conference on Analytical Chemistry) with Guest Editor Paweł Koscielniak.

K. Lech $\cdot$ M. Jarosz $(\bowtie)$

Chair of Analytical Chemistry, Faculty of Chemistry,

Warsaw University of Technology,

Noakowskiego 3,

Warsaw 00-664, Poland

e-mail: mj@ch.pw.edu.pl

K. Lech

e-mail: klech@ch.pw.edu.pl the so-called "dcII" component of cochineal as a $C$-glucose derivative of flavokermesic acid.

Keywords Archaeometry ·dcII - Extraction .

HPLC-UV-Vis-ESI MS · Natural dyestuffs · Polish cochineal

\section{Introduction}

Contemporary art work preservation techniques are based not only on historical or technological research, but also on the results of chemical examination of their structure. As for the latter, the identification of colorants that were used for dyeing textiles is critical. As most dyestuffs contain more than one coloring matter, analytical techniques applied to their identification must comprise both separation and detection steps. Nowadays, one of the most significant tools allowing separation of colorants is high-performance liquid chromatography (HPLC), for the first time used for this purpose by Wouters $[1,2]$. As for detection, spectrophotometric (UV-Vis) [3-9] or mass spectrometric (MS) [10-16] instruments are the most common. Both the techniques are useful in dyes analyses; however, MS detectors, more selective and often also more sensitive than the UV-Vis ones, additionally provide information which enables elucidation of the examined colorants structures.

Analytical results obtained by HPLC systems (regardless of detector type) mostly depend on the extraction procedure. The sample preparation determines quality and quantity of isolated colorants. For many years, the treatment of fibers with a mixture of methanol, water and hydrochloric acid $\left(\mathrm{MeOH} / \mathrm{H}_{2} \mathrm{O} / 37 \% \mathrm{HCl}, 1: 1: 2, v / v / v\right)$ was the most often used procedure [1-3, 6, 17-19]. Such extraction was dedicated to mordant dyes (flavonoids and anthraquinones), but in the case of indigoid dyes, whose 
colorants are more hydrophobic, it proved to be not efficient enough. Better results were obtained when the mixture of $\mathrm{MeOH} / \mathrm{H}_{2} \mathrm{O}$ was replaced by DMSO, DMF or its mixtures with methanol $[6,11,12]$. Those acidic procedures allow extraction only of aglycones; all of the colorants present as sugar derivatives (i.e., only $O$-glycosides) are hydrolyzed with $\mathrm{HCl}$ solution. They can offer high efficiency of the extraction, but provide less detailed information, which could be helpful for distinction of dyes. Hence, for the last couple of years, studies have been devoted to modification of this traditional procedure and change of hydrochloric to other, milder acids. At first, fibers dyed by various mordant preparations were treated with methanol-aqueous solutions of EDTA and of formic acid [18]. As it turned out, both the procedures gave similar results, but EDTA was slightly better for flavonoid dyes, while formic acid was more efficient in the case of anthraquinones. The latter extraction method was successfully used in subsequent research of archaeological textiles [14, 20]. Among other substances which were of interest to analysts were also trifluoroacetic acid (TFA), citric acid and a combination of formic acid and EDTA [21] as well as oxalic acid [16, 21]. They were tested on wool and silk threads dyed with red and yellow mordant dyes as well as turmeric and woad. The obtained results allowed to recommend the TFA method as possibly the best extraction procedure for most of examined compounds. However, the research was conducted only with spectrophotometric detection; this extraction method could not be used with ESI MS detector, because of the negative effect of TFA on the efficiency of ionization, which was diminished as a result of strong ion-pairs formation between TFA and colorant molecules [22].

All of the aforementioned procedures, after extraction performed in elevated temperature (between 40 and $100{ }^{\circ} \mathrm{C}$ ) contained evaporation step, after which the residues were dissolved in methanol, methanol-water or methanol-DMF mixtures. This was to eliminate acid, which was entered to the column, and at the same time to allow concentration of the sample.

Recently, studies have also been focused on other extraction methods. Apart from common LLE with popular solvents (water, methanol, ethanol) and their mixtures [23], ultrasound and supercritical $\mathrm{CO}_{2}$ extraction were examined [24], but only for a few anthraquinones (aloe-emodin, emodin, rheine, chrysophanol, and physcione) in a raw plant material. Microwave-assisted extraction was used for isolation of alizarin and purpurin from Rubiaceae plants [25].

HPLC coupled with UV-Vis or/and MS detectors is a powerful tool for separation and identification of color agents of different classes, such as anthraquinones, flavonoids, carotenoids, anthocyanins or indigoids. Because of the multiplicity of colorants (even within dyes of one color), the method used for their examination involves differentiation between many compounds, which prolongs the analysis even up to about an hour $[4,7,9,12,14,15]$. So far, those analyses in which the procedure times were relatively short, either dealt with separation of only a few analytes $[3,5,6,8]$, or used solvents with high elution strength, but more expensive, such as acetonitrile $[3,8,10$, $11,13,16]$. The aim of the present study was to design a new extraction procedure and a modified HPLC-UV-VisMS method (based on a water-methanol eluent recommended also as a solvent enhancing ionization efficiency in ESI source in higher degree than acetonitrile system [22]), as universal as possible, for identification of a wide group of colorants present in various natural dyestuffs (Fig. 1), potentially used for dyeing the most valuable textiles produced in the fifteenth and sixteenth centuries in Italy. The developed method was applied for studying selected chasubles (intended for cataloging and conservation) from the Treasury of the Wawel Cathedral (Cracow, Poland), which were made for the royal court of the Jagiellonian dynasty reigning in Poland in the years 1386-1572.

\section{Experimental}

\section{Apparatus}

Separation and identification of the colorants were carried out using a liquid chromatographic system with mass spectrometric and spectrophotometric detection. The optimized parameters of the developed method are presented in Table 1. The samples were injected onto a column using an injection valve, Rheodyne Model 7225i (Cotati, CA, USA). The mobile phase was degassed with the use of Micro Vacuum Degasser 1100 (Agilent Technologies, USA), and the gradient program was controlled by the LC ChemStation 3D software (HewlettPackard, USA). The detectors (VWD 1200 and MSD 1100 Agilent Technologies) were stopped after $27 \mathrm{~min}$, the eluents were being restored to the initial composition for the next $3 \mathrm{~min}$, and then the column was equilibrated for $5 \mathrm{~min}$.

Spectrophotometric spectra of the colorants were registered within the range of 240 to $700 \mathrm{~nm}$ with the use of Lambda 20 UV-Vis spectrophotometer (Perkin-Elmer, USA). The scan speed and the slit width were $120 \mathrm{~nm} \mathrm{~min}{ }^{-1}$ and $2 \mathrm{~nm}$, respectively.

The extraction of the colorants from the fibers was performed with the use of an ultrasonic bath, Branson Model 1210 (Danbury, USA), as well as with a water bath, Memmert WB 10 (Schwabach, Germany).

Chemicals and materials

Quercetin, genistein, luteolin, kaempferol, apigenin, ellagic acid, gallic acid, indigotin, isatin, carminic acid, purpurin, 
Fig. 1 Structures of examined colorants<smiles></smiles><smiles>O=C1Nc2ccccc2C1=C1C(=O)Nc2ccccc21</smiles><smiles>O=C1C(=C2Nc3cc(Br)ccc3C2=O)Nc2cc(Br)ccc21</smiles>
$\mathrm{H}$ Isoindigotin<smiles>Oc1cc2c(cc1O)[C@H]1c3ccc(O)c(O)c3OC[C@@]1(O)C2</smiles><smiles>O=C1Nc2ccccc2C1=O</smiles>
6,6'-Dibromoindigotin

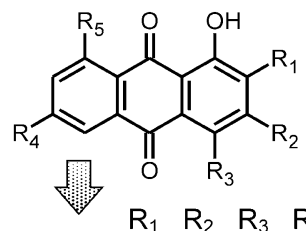
$\begin{array}{lllll}R_{1} & R_{2} & R_{3} & R_{4} & R_{5}\end{array}$<smiles>O=C1C=C2C(=CC1O)C1=C3c4ccc(O)c(O)c4OCC3(O)CC21</smiles><smiles>O=C1Oc2c(O)c(O)cc3c2c(=O)oc2c(O)c(O)cc1c23</smiles>

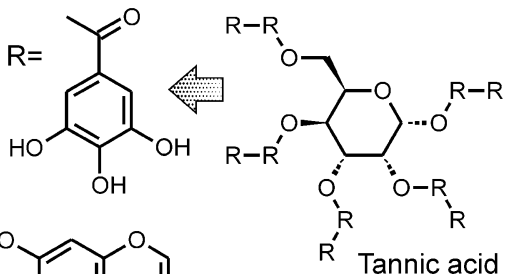
Plizarin $\mathrm{OH} \mathrm{H} \mathrm{OH} \mathrm{H}^{-}$ Emodin $\mathrm{H} \mathrm{OH} \mathrm{H} \mathrm{CH}_{3} \mathrm{OH}$<smiles>[R]Cc1c(O)c([R7])c2c(c1O)C(=O)c1cc(O)c(C(=O)O)c([R])c1C2=O</smiles><smiles>[Y]C1OC(CO)C(O)C(O)C1O</smiles><smiles>CCCNC(C)=O</smiles><smiles>O=c1c(-c2ccc(O)cc2)coc2cc(O)cc(O)c12</smiles>

Flavokermesic acid Kermesic acid Carminic acid Laccaic acid $\mathrm{A}$ Laccaic acid B Laccaic acid C Xantholaccaic acid $A$ S $Y_{1} H_{1}$ Xantholaccaic acid $B \quad Y_{2} \quad H \quad C O O H$ 6-Bromoisatin<smiles>O=C(O)c1cc(O)c(O)c(O)c1</smiles>

Gallic acid<smiles>O=C1Nc2cc([123I])ccc2C1=O</smiles>
Genistein<smiles></smiles>
$\mathrm{OH} \mathrm{H} \mathrm{OH}$ OH OH Quercetin $\mathrm{H} \mathrm{OH} \mathrm{OH} \mathrm{OH} \mathrm{OH}$ Luteolin $\mathrm{H} \mathrm{OH} \mathrm{OH} \mathrm{H} \mathrm{OH}$ Kaempferol $\mathrm{H} \quad \mathrm{H} \quad \mathrm{OH} \mathrm{OH} \mathrm{OH}$ Apigenin $\mathrm{H} \quad \mathrm{H} \quad \mathrm{OH} H \quad \mathrm{OH}$ Diosmetin $\mathrm{H} \mathrm{OH} \mathrm{OCH} 3 \mathrm{H} \mathrm{OH}$ Rhamnetin $\mathrm{H} \mathrm{OH} \mathrm{OH} \mathrm{OH} \mathrm{OCH}$ and emodin were purchased from Fluka (Buchs, Switzerland); rhamnetin and diosmetin-from ChromaDex (Santa Ana, CA, USA); tannic acid, alizarin, and hematoxylin-from Riedel-de Haën (Seelze, Germany); hematein (approx. 85\%) - from Sigma (St. Louis, MO, USA); morin - from Aldrich (Steinheim, Germany). All the chemicals (except alizarin) were of analytical chemical grade. Indirubin and isoindigotin had been synthesized earlier by Puchalska [11], and their chromatographic purity was estimated by the HPLC/DAD at $280 \mathrm{~nm}$. Kermesic acid and 6,6'-dibromoindigo were kindly donated by Dr. Ioannis Karapanagiotis ("Ormylia" Art Diagnosis Centre, Greece). 6-Bromoisatin was obtained as a result of a 30-day exposure of Tyrian purple solution to the sun light; laccaic acids A, B, C and flavokermesic acid were a mixture obtained from a natural product, lac dye. Tyrian purple, lac dye, and weld were purchased from KremerPigmente (Aichstetten, Germany).

Formic acid (98-100\%) and hydrochloric acid of analytical chemical grade were purchased from AppliChem (Darmstadt, Germany). Dimethylsulfoxide and methanol of super gradient purity as well as potassium alum of analytical chemical grade came from POCh (Gliwice,
Poland). Demineralized water was obtained from Milli-Q system Model Millipore Elix 3 (France).

\section{Examined historical art works}

The examined textiles belong to the chasubles collection of the Treasury of the Wawel Cathedral (Cracow, Poland). The green, red, and violet fibers were taken from fabrics classified as Italian velvet brocades and dated as follows [26]:

- Red fiber (registration number KKK tk/46) — the end of the fifteenth century,

- Violet fiber (registration number KKK tk/237) - the second half or the end of the fifteenth century,

- Green fiber (registration number KKK tk/54) - the second half or the end of the fifteenth century

Dyestuffs and standards preparation

Solutions of most of the dyestuffs and their color components (standards) were prepared by dissolving $2 \mathrm{mg}$ 
Table 1 Conditions for separation and detection of examined colorants of each powder in $10 \mathrm{~mL}$ of a selected solvent. Dimethylsulfoxide was used for indigotin, indirubin, isoindigo, 6,6'dibromoindigotin, and Tyrian purple, while methanol for other standards and lac dye.

The obtained solutions were filtered over a $0.45 \mu \mathrm{m}$ syringe filter (Supelco, Sigma-Aldrich, Bellefonte, PA, USA). The first five drops were discarded, and only the remaining parts of the filtrates were used for the analysis.

Mordanting and dyeing of wool fibers

Fibers were mordanted and dyed according to [27]. An alum mordant was prepared by dissolving $3 \mathrm{~g}$ of potassium alum in $200 \mathrm{~mL}$ of water. Wool samples (about $1.5 \mathrm{~g}$ ) were wetted and then were being immersed in the mordant solution at $90{ }^{\circ} \mathrm{C}$ for $60 \mathrm{~min}$. After that, the fibers were washed and then dyed in the previously obtained weld extract.

The dye bath was prepared with the extraction of $1 \mathrm{~g}$ of dried weld in $50 \mathrm{~mL}$ of water. It was being heated at $90{ }^{\circ} \mathrm{C}$ for $30 \mathrm{~min}$, and then strained through a filter paper. Mordanted wools were put into the bath and they were being dyed in $90{ }^{\circ} \mathrm{C}$ for the next $60 \mathrm{~min}$. After that, the fibers were taken out from the solutions, carefully washed (at first in a detergent and than in pure water) and dried.

\section{Results and discussion}

Method development

The solutions of the available standards were characterized spectrophotometrically. Their absorption maxima are shown in Table 2. According to the collected data, the colorants were classified as belonging to the following groups: soft yellow, deep yellow/orange, red, and blue, and for their detection the following wavelengths were chosen: $370,430,500,550$, and $600 \mathrm{~nm}$, respectively. Chromato- 
Table 2 Characterization of eluted compounds shown as subsequent peaks in Fig. 2

\begin{tabular}{|c|c|c|c|c|c|c|c|c|}
\hline \multirow{2}{*}{$\begin{array}{l}\text { Peak } \\
\text { no. }\end{array}$} & \multirow[t]{2}{*}{ Compound } & \multirow[t]{2}{*}{$t_{\mathrm{R}(\min )}$} & \multirow{2}{*}{$\begin{array}{l}\text { Isotopic } \\
\text { molecular } \\
\text { mass }\end{array}$} & \multicolumn{2}{|c|}{ Negative ions $(m / z)$} & \multicolumn{2}{|c|}{ Positive ions $(\mathrm{m} / \mathrm{z})$} & \multirow[t]{2}{*}{$\lambda_{\max }(\mathrm{nm})$} \\
\hline & & & & {$[\mathrm{M}-\mathrm{H}]^{-}$} & other & {$[\mathrm{M}+\mathrm{H}]^{+}$} & other & \\
\hline & Tannic acid & $6.3-9.1$ & 1700 & & $\begin{array}{l}169[\mathrm{G}-\mathrm{H}]^{-} \\
321\left[2 \mathrm{G}-\mathrm{H}-\mathrm{H}_{2} \mathrm{O}\right]^{-}\end{array}$ & & $\begin{array}{l}153\left[\mathrm{G}+\mathrm{H}-\mathrm{H}_{2} \mathrm{O}\right]^{+} \\
449\left[\mathrm{M}+\mathrm{H}-2 \mathrm{G}-6\left(\mathrm{G}-\mathrm{H}_{2} \mathrm{O}\right)\right]^{+}\end{array}$ & 274 \\
\hline & & & & & $483\left[\mathrm{M}-\mathrm{H}-8\left(\mathrm{G}-\mathrm{H}_{2} \mathrm{O}\right)\right]^{-}$ & & $467\left[\mathrm{M}+\mathrm{H}-\mathrm{G}-7\left(\mathrm{G}-\mathrm{H}_{2} \mathrm{O}\right)\right]^{+}$ & \\
\hline & & & & & $635\left[\mathrm{M}-\mathrm{H}-7\left(\mathrm{G}-\mathrm{H}_{2} \mathrm{O}\right)\right]^{-}$ & & $619\left[\mathrm{M}+\mathrm{H}-\mathrm{G}-6\left(\mathrm{G}-\mathrm{H}_{2} \mathrm{O}\right)\right]^{+}$ & \\
\hline & & & & & $787\left[\mathrm{M}-\mathrm{H}-6\left(\mathrm{G}-\mathrm{H}_{2} \mathrm{O}\right)\right]^{-}$ & & $771\left[\mathrm{M}+\mathrm{H}-\mathrm{G}-5\left(\mathrm{G}-\mathrm{H}_{2} \mathrm{O}\right)\right]^{+}$ & \\
\hline & & & & & $939\left[\mathrm{M}-\mathrm{H}-5\left(\mathrm{G}-\mathrm{H}_{2} \mathrm{O}\right)\right]^{-}$ & & $923\left[\mathrm{M}+\mathrm{H}-\mathrm{G}-4\left(\mathrm{G}-\mathrm{H}_{2} \mathrm{O}\right)\right]^{+}$ & \\
\hline & & & & & $1091\left[\mathrm{M}-\mathrm{H}-4\left(\mathrm{G}-\mathrm{H}_{2} \mathrm{O}\right)\right]^{-}$ & & $1075\left[\mathrm{M}+\mathrm{H}-\mathrm{H}_{2} \mathrm{O}-4\left(\mathrm{G}-\mathrm{H}_{2} \mathrm{O}\right)\right]^{+}$ & \\
\hline 1 & Gallic acid & 5.9 & 170 & 169 & $125\left[\mathrm{M}-\mathrm{H}-\mathrm{CO}_{2}\right]^{-}$ & & $153\left[\mathrm{M}+\mathrm{H}-\mathrm{H}_{2} \mathrm{O}\right]^{+}$ & 273 \\
\hline 2 & Hematoxylin & 7.0 & 302 & 301 & & 303 & $325[\mathrm{M}+\mathrm{Na}]^{+}$ & 292,445 \\
\hline 3 & Laccaic acid $\mathrm{c}$ & 8.2 & 539 & 538 & $494\left[\mathrm{M}-\mathrm{H}-\mathrm{CO}_{2}\right]^{-}$ & 540 & $562[\mathrm{M}+\mathrm{Na}]^{+}$ & $-^{\mathrm{a}}$ \\
\hline 4 & Hematein & 8.8 & 300 & 299 & & 301 & & 282,427 \\
\hline 5 & Isatin & 9.1 & 147 & 146 & & 148 & $170[\mathrm{M}+\mathrm{Na}]^{+}$ & 296,413 \\
\hline 6 & Carminic acid & 9.6 & 492 & 491 & $447\left[\mathrm{M}-\mathrm{H}-\mathrm{CO}_{2}\right]^{-}$ & 493 & $515[\mathrm{M}+\mathrm{Na}]^{+}$ & 276,497 \\
\hline 7 & $\begin{array}{l}\text { Xantholaccaic } \\
\text { acid B }\end{array}$ & 10.1 & 480 & 479 & $435\left[\mathrm{M}-\mathrm{H}-\mathrm{CO}_{2}\right]^{-}$ & 481 & $503[\mathrm{M}+\mathrm{Na}]^{+}$ & $-^{\mathrm{a}}$ \\
\hline 8 & $\begin{array}{l}\text { Xantholaccaic } \\
\text { acid A }\end{array}$ & 10.2 & 521 & 520 & $476\left[\mathrm{M}-\mathrm{H}-\mathrm{CO}_{2}\right]^{-}$ & 522 & $544[\mathrm{M}+\mathrm{Na}]^{+}$ & $-^{\mathrm{a}}$ \\
\hline 9 & Laccaic acid B & 10.6 & 496 & 495 & $451\left[\mathrm{M}-\mathrm{H}-\mathrm{CO}_{2}\right]^{-}$ & 497 & $519[\mathrm{M}+\mathrm{Na}]^{+}$ & $-^{\mathrm{a}}$ \\
\hline 10 & Laccaic acid A & 10.7 & 537 & 536 & $492\left[\mathrm{M}-\mathrm{H}-\mathrm{CO}_{2}\right]^{-}$ & 538 & $560[\mathrm{M}+\mathrm{Na}]^{+}$ & $281,494^{\mathrm{a}}$ \\
\hline 11 & Ellagic acid & 11.7 & 302 & 301 & & 303 & $325[\mathrm{M}+\mathrm{Na}]^{+}$ & 255,366 \\
\hline 12 & Morin & 12.6 & 302 & 301 & & 303 & $325[\mathrm{M}+\mathrm{Na}]^{+}$ & 263,361 \\
\hline 13 & Bromoisatin & 12.7 & $225 / 227$ & 224,226 & $196,198[\mathrm{M}-\mathrm{H}-\mathrm{CO}]^{-}$ & 226,228 & $248,250[\mathrm{M}+\mathrm{Na}]^{+}$ & $263,305,376$ \\
\hline 14 & Quercetin & 13.7 & 302 & 301 & & 303 & $325[\mathrm{M}+\mathrm{Na}]^{+}$ & 256,371 \\
\hline 15 & Luteolin & 14.7 & 286 & 285 & & 287 & $309[\mathrm{M}+\mathrm{Na}]^{+}$ & 256,348 \\
\hline 16 & Genistein & 14.9 & 270 & 269 & & 271 & $293[\mathrm{M}+\mathrm{Na}]^{+}$ & 261 \\
\hline 17 & Kaempferol & 15.9 & 286 & 285 & & 287 & $309[\mathrm{M}+\mathrm{Na}]^{+}$ & 266,367 \\
\hline 18 & $\begin{array}{l}\text { Flavokermesic } \\
\text { acid }\end{array}$ & 16.5 & 314 & 313 & $269\left[\mathrm{M}-\mathrm{H}-\mathrm{CO}_{2}\right]^{-}$ & 315 & $337[\mathrm{M}+\mathrm{Na}]^{+}$ & $-^{\mathrm{a}}$ \\
\hline 19 & Apigenin & 16.7 & 270 & 269 & & 271 & $293[\mathrm{M}+\mathrm{Na}]^{+}$ & 268,334 \\
\hline 20 & Kermesic acid & 16.9 & 330 & 329 & $285\left[\mathrm{M}-\mathrm{H}-\mathrm{CO}_{2}\right]^{-}$ & 331 & & 274,492 \\
\hline 21 & Diosmetin & 17.0 & 300 & 299 & & 301 & $323[\mathrm{M}+\mathrm{Na}]^{+}$ & $252,268,292,343$ \\
\hline 22 & Rhamnetin & 18.5 & 316 & 315 & & 317 & $339[\mathrm{M}+\mathrm{Na}]^{+}$ & 256,372 \\
\hline 23 & Isoindigotin & 18.6 & 262 & 261 & & 263 & $285[\mathrm{M}+\mathrm{Na}]^{+}$ & $274,368,490$ \\
\hline 24 & Alizarin & 19.6 & 240 & 239 & & 241 & $263[\mathrm{M}+\mathrm{Na}]^{+}$ & 245,429 \\
\hline 25 & Indigotin & 21.0 & 262 & 261 & & 263 & $285[\mathrm{M}+\mathrm{Na}]^{+}$ & 291,620 \\
\hline 26 & Purpurin & 22.4 & 256 & 255 & & 257 & & 291,482 \\
\hline 27 & Indirubin & 22.6 & 262 & 261 & & 263 & $285[\mathrm{M}+\mathrm{Na}]^{+}$ & 257,550 \\
\hline 28 & Emodin & 23.7 & 270 & 269 & & 271 & $293[\mathrm{M}+\mathrm{Na}]^{+}$ & 288,435 \\
\hline 29 & $\begin{array}{l}6,6^{\prime}- \\
\text { Dibromoindigotin }\end{array}$ & 24.4 & $\begin{array}{l}418 / 420 / \\
422\end{array}$ & $417,419,421$ & & $419,421,423$ & & $306,348,610$ \\
\hline
\end{tabular}

$G$ gallic acid

${ }^{\text {a }}$ Color compounds isolated from lac dye preparation (mixture of laccaic acids with domination of laccaic acid A)

grams were also registered at $280 \mathrm{~nm}$, as gallic and tannic acids exhibit strong absorption at this wavelength being not detectable in the visible region. Moreover, most of colorants absorb at $280 \mathrm{~nm}$ and their K-band(s) are significantly stronger than R-band(s) in the Vis range [28]. Detection at this wavelength, even being unspecific, is much more sensitive than performed in visible range, and allows to register also substances from outside group of examined standards.

The initial settings of HPLC separation and MS detection were based on those proposed earlier by Pawlak et al. [12]. However, several changes and improvements had to be made in the gradient program in order to enable identification of a wider palette of color compounds over 
shorter time. A formic acid content used as an acidic modifier was found as a critical parameter in the optimization process. Its presence and concentration essentially affected the sensitivity of electrospray mass spectrometry (ESI MS) detection.

During the optimization of the mobile phase composition, the percentage of formic acid in a water-methanol mixture was being changed as follows: $0.00 \%, 0.05 \%$, $0.10 \%, 0.15 \%$, and $0.25 \%$. The best ionization efficiency of gallic and ellagic acid in the negative-ion MS mode was registered when the concentration of formic acid in the eluent equaled $0.10 \%$. The optimal concentration for identification of laccaic acids was $0.25 \%$. The most intense signals of carminic, flavokermesic, and kermesic acids were obtained when formic acid content was kept in the range between $0.10 \%$ and $0.25 \%$. These results differed from those previously reported by Rafaëlly et al. [29], but the gradient program they used was based on acetonitrile instead of methanol. The signals were not discernible when acidic modifier was not added to the mobile phase, which was also noticed in the cited paper. It appears to have been linked with the presence of carboxylic groups in their structures.

Anthraquinones, such as alizarin, purpurin or emodin, were ionized more easily when $0.05 \%$ of formic acid was in the eluent. Similar observation was made in the case of hematein and hematoxylin; nonetheless, their ionization efficiencies were extremely low anyway, which resulted in very weak signals. For these compounds, spectrophotometric detection was much more sensitive, and for this reason dual detection system was used in the developed procedure.

In the negative-ion ESI MS mode, flavonoids were the most easily ionizable compounds among the examined colorants, but the intensity of signals corresponding to their quasi-molecular ions were the highest when a pure watermethanol mixture without acidic additive was used as an eluent (it is worth noticing that such a result was completely opposite to the results concerning the colorants discussed above). A similar phenomenon was also observed for indigoid compounds, but in their case the signal intensity was very weak. Hence, for identification of those colorants, the positive ion mode was found to be more proper, and the concentration of formic acid in the eluent was kept between $0.05 \%$ and $0.10 \%$.

Taking the above into consideration, since the eluent should be "universal" for chemically different compounds, it was decided that $0.10 \%$ of formic acid in the methanolwater mixture would be used for subsequent analyses.

Examination of the compounds by HPLC (C18 reversedphase column) coupled with a single band UV-Vis spectrophotometer and electrospray mass spectrometer was the second step of method optimization. Such a system allowed identification of 29 colorants in the standards mixture (Fig. 2). Most of them were detected at $280 \mathrm{~nm}$. Apart from that, spectra of individual color compounds were registered in a visible range (Table 2). Flavonoids were observed at $370 \mathrm{~nm}$, emodin and alizarin, as well as isatin and bromoisatin at $430 \mathrm{~nm}$, while anthraquinones and indirubin at 430 and $500 \mathrm{~nm}$. Indirubin was registered at 500,550 (the highest peak), and $600 \mathrm{~nm}$. For indigotin, $600 \mathrm{~nm}$ was an optimal wavelength. Isoindigotin was registered at almost all of the used wavelengths, except $600 \mathrm{~nm}$ (Fig. 2d).

Tannic acid, as a compound unstable under chromatographic conditions, was analyzed individually (Fig. 2b). As a result of its breakdown, various fragments of the parent molecule were present in the eluate. In addition, also during ionization in ESI source, further fragmentation occurred. The main ions registered in MS spectra are shown in Table 2 without any peak number ascribed, since tannic acid was registered as an unusually wide and asymmetrical peak.

It has to be noted that even the optimized procedure did not ensure perfect separation of all the examined compounds, as some of them were co-eluted. For their proper identification, it was necessary to use both the detection techniques, and in the case of MS both positive- and negative ionization modes.

Some of the co-eluted colorants could be distinguished thanks to visible detection, especially when the compounds belonged to various groups and differed significantly. In the present study, flavokermesic acid and kermesic acid were effectively separated from each other, and the time interval between their peaks was $0.4 \mathrm{~min}$, but in the mixture of standards they co-eluted with flavonoids. However, solutions of flavokermesic and kermesic acids absorbed at $430 \mathrm{~nm}$, while co-eluted apigenin and diosmetin at $370 \mathrm{~nm}$. Moreover, MS detection and reconstruction of the chromatograms for each of their quasi-molecular ions (Table 2) allowed accurate identification of all the species. The same procedure was also found to be efficient in differentiation of yet another pair of co-eluted compounds, i.e., genistein and luteolin.

The ions (mostly quasi-molecular, rarely fragment ions) registered for the examined standards in both ionization modes are presented in Table 2. They were used to develop the final method for identification of colorants in art works. These ions, together with the characteristic ones identified in methanolic extract of madder (at $\mathrm{m} / \mathrm{z} 253,283$ and 563 in NI mode) and cochineal (at $m / z$ 475, 431 in NI mode) were comprised in the selective ion monitoring (SIM) method.

\section{Extraction procedures}

The extraction procedure was optimized for fibers dyed with weld and madder. Formic or hydrochloric acid was 
Fig. 2 Chromatograms of color standards registered under optimal conditions by using detectors: MS $a, b, c$, and UV-Vis $d$. Description of the peaks is given in Table 2; TIC total ion current, $N I$ negative ion mode, $P I$ positive ion mode

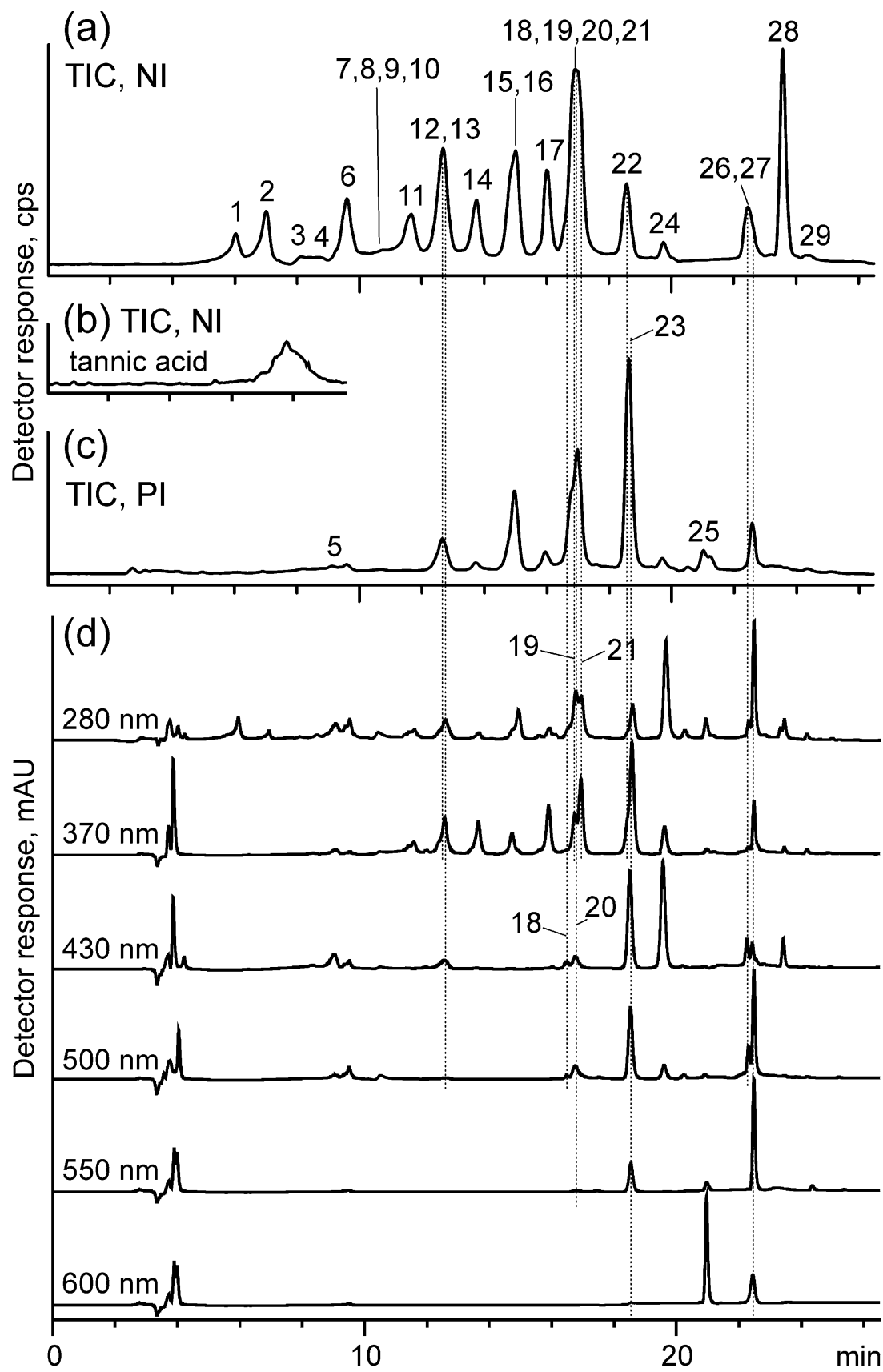

added to each extract in an amount of $2 \%, 5 \%, 10 \%$, or $15 \%$ by volume. The process was assisted by ultrasound for $5,10,20$, or $30 \mathrm{~min}$, and heated at $50,60,70$, or $80^{\circ} \mathrm{C}$ for $10,25,40$, or $55 \mathrm{~min}$. As flavonoid and anthraquinone colorants differed substantially as well as they needed different extraction temperature and acid concentrations in the solvent, it was decided to choose average values of the optimized parameters, which would be the most "universal" for all dyes.

Regardless of the extraction conditions or used acid, in the chromatograms of the extracts peak intensities were significantly lower when they were evaporated and residues dissolved in methanol, than in the chromatograms of the solutions obtained just after extraction (Fig. 3). Evaporation to dryness was performed according to accepted procedure $[4,10,13,18,30]$ by heating under vacuum over sodium hydroxide pellets. These low intensities were registered even when methanol volume used for dissolution of the residue was four times smaller than initial volume of the acidic extracts. Similar phenomenon was observed not only for weld, but also in the case of other dyes, and for that reason the evaporation step was omitted in the developed procedure.

According to expectation the use of mild extraction allowed to register more peaks than the hydrochloric acid 


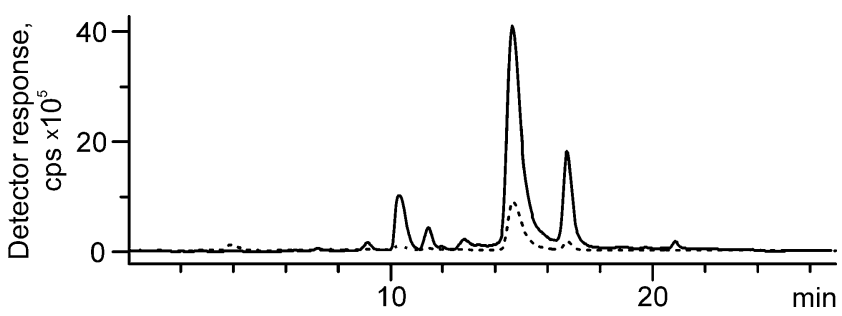

Fig. 3 Chromatograms of formic acid extract of wool dyed with weld: without evaporation and dissolution of the residues (solid line) and with evaporation (dotted line) registered with ESI MS detection in the negative-ion mode

procedure. In chromatograms of weld extract, apart from two major peaks of luteolin and apigenin, also signals of their glycoside derivatives were registered (Fig. 3). The most intense, eluted at $10.3 \mathrm{~min}$, corresponded to luteolin-7-Oglucoside, and the next one, at $11.4 \mathrm{~min}$, was identified as a peak of apigenin-7-O-glucoside. Substances eluted in peaks at 9.2 and 12.8 min were identified on the base of their mass spectra. When orifice voltage was fixed at $90 \mathrm{~V}$, in the mass spectra of the compounds eluted in the first and second peaks, single signals were registered, at $\mathrm{m} / \mathrm{z} 609$ and 447, respectively. Increase of the voltage to $200 \mathrm{~V}$ allowed to register also fragment ions: at $\mathrm{m} / \mathrm{z} 447$ and 285 for the first peak and at $m / z 285$ for the second one. The obtained results allowed to postulate, that luteolin-di- $O$-glucoside was eluted in the first peak (probably luteolin-3',7-di- $O$-glucoside, according to [16]), and in the second-luteolin- $O$-glucoside.

It was obvious that the extraction with hydrochloric acid was the more effective procedure, but at the same time it caused hydrolysis of almost all glycoside derivatives of the colorants. On the other hand, the process performed with the use of formic acid, although less effective, allowed obtaining more information concerning intact forms of colorants present in natural preparations. Taking into account both the milder character of procedure with formic acid and the much more better extraction efficiency with hydrochloric acid, a two-step protocol was designed. In this way, information about potential glycoside compounds were obtained and at the same time losses in the amount of the compounds arising from this extraction did not affect significantly the quality of the extract with hydrochloric acid. The use of the same fiber twice in two different extractions helped to minimize the amount of sample and simultaneously allowed obtaining all necessary information.

Hence, the final extraction procedure was as follows. A $0.1-\mathrm{mg}$ sample of fiber was extracted by $50 \mu \mathrm{L}$ of a mixture of methanol and formic acid $(9: 1, v / v)$. It was being kept in an ultrasonic bath for $5 \mathrm{~min}$ and then in a water bath (at $60{ }^{\circ} \mathrm{C}$ ) for the next $30 \mathrm{~min}$. The fiber was taken out of the solution and extracted again by $50 \mu \mathrm{L}$ of a mixture of methanol and hydrochloric acid of $37 \%(7: 1, v / v)$, using the same procedure as described above. Each of the obtained solutions was diluted with $50 \mu \mathrm{L}$ of methanol.

Analysis of textiles

The developed method was applied to identification of dyes present in three fibers: red, violet, and green from historical chasubles from the Wawel Cathedral treasury collection. The red one was taken from textile dated at the end of the fifteenth century, green and violet — dated at the second half or the end of the fifteenth century.

The extracts of the samples were examined by the HPLC-UV-Vis-ESI MS method (SIM in the negative and positive modes). In the extract of the red sample, obtained with the use of methanol-hydrochloric acid mixture, two peaks were observed when spectrophotometric detection at $500 \mathrm{~nm}$ was used. The first and the most intense peak was identified as corresponding to carminic acid, and the second one to kermesic acid. The same compounds were present in the MS chromatogram (TIC, NI mode; Fig. 4a). Their signals were registered for the ions at $m / z 491$ and 329 (and weaker, not shown, at $m / z 285$ ), respectively. Furthermore, the third peak shown in the chromatogram was identified as ellagic acids $(m / z$ 301). Another small peak eluting at 16.5 min was unnoticed at first, but after the reconstruction of the chromatograms for the ions at $m / z 313$ and 269 it was determined as flavokermesic acid.

Reconstruction of the chromatogram for the ion at $\mathrm{m} / \mathrm{z}$ 491 and the enlargement of the base line showed two substantially smaller peaks at 11.5 and $12.7 \mathrm{~min}$. Probably, they corresponded to dcIV and dcVII, respectively; their structures have not been discovered yet. Also dcII was identified in the extracts (registered as the peak at $9.4 \mathrm{~min}$ ). Its presence could be proved by the reconstruction of the chromatogram for the ion at $m / z 475$, attributed to quasimolecular of dcII by Peggie et al. [19, 31]. Taking into account that carminic acid is a $C$-glucose derivative of kermesic acid, structure of dcII proposed by Peggie et al. [19] as a $C$-glucose derivative of flavokermesic acid, seems to be well-founded. More specifically, dcII is likely to be 7$\alpha$-D-glucopyranosyl flavokermesic acid.

The structure of dcII was confirmed by the negative mass spectra registered with a higher orifice voltage, i.e. $240 \mathrm{~V}$. In the case of carminic acid, apart from the intensive signal of the quasi-molecular ion $(\mathrm{m} / \mathrm{z} 491)$, the ion at $\mathrm{m} / \mathrm{z}$ 447 formed by the loss of $\mathrm{CO}_{2}$ was also observed. Since carminic acid is a $C$-glucose derivative of kermesic acid, its fragmentation path differs from the ones of an $O$-derivative. $O$-derivatives form mainly fragments corresponding to "aglycone ions", formed by cleavage of glycosidic bond. In the case of $C$-derivative, the main fragments are formed by cross-ring cleavages of a sugar units, because $\mathrm{C}-\mathrm{C}$ bond is stronger than $\mathrm{C}-\mathrm{O}$. Such a fragmentation was observed in 
Fig. 4 Chromatograms of extracts of red (a) and purple (b) fibers registered with UV-Vis and ESI MS detection; TIC total ion current, EIC extracted ion chromatogram, NI negative ion mode, $P I$ positive ion mode, $F A$ extract obtained by use of methanol-water with formic acid, $H A$ with hydrochloric acid

the mass spectrum of carminic acid (see Fig. 5a), where ions at $\mathrm{m} / \mathrm{z} 357,327$ and 299 were observed. Analogical ions were recorded in the mass spectrum of dcII (see Fig. 5b), but their $m / z$ values were of 16 units smaller than those registered in the spectrum of carminic acid (Table 3). The obtained was data was in accordance with the published previously $[19,30]$.

In the mass spectra of dcIV and dcVII, exactly the same signals were observed as in the carminic acid one. It led to the hypothesis that they were probably isomers of carminic acid with sugar moieties bonded with carbon atom in another position.

The content of red colorants in the obtained extracts was determined spectrophotometrically by the use of external standard method. Calculations were performed for the chromatograms registered at 280 and $500 \mathrm{~nm}$ for the extracts obtained with formic acid or hydrochloric acid, and the results were then added up (it has to be noted, that in the examined extract, any other colorants apart from those discussed above were detected, especially those coeluting with kermesic acid). The calibration plots of carminic and kermesic acids were linear (the $r$ values were always higher than 0.995) in the whole range of their concentrations $\left(2.5-40.0 \mu \mathrm{g} \mathrm{mL}^{-1}\right)$. Because of the lack of standards for dcIV, dcVII, and flavokermesic acid, their calibration plots were prepared with use of extracts from American cochineal and lac dye, which were diluted twice in each of the five dilution steps. The content of carminic acid was estimated at $71-75 \%$ and of kermesic acid at $22-$ $27 \%$. The sum of all other cochineal colorants was approximately between $1 \%$ and $3 \%$.

The presence of carminic acid, the high content of kermesic acid as well as the appearance of flavokermesic acid, dcII, dcIV and dcVII led to the conclusion that the fiber was dyed with Polish cochineal. According to Hofenk de Graaff [17] and Cardon [32] this dyestuff contains more kermesic acid than Armenian cochineal, in which its content does not exceed $2.0 \%$. Moreover, the content of flavokermesic acid can come up even to $4.6 \%$, while in Polish cochineal it is rather lower than the content of kermesic acid [30]. However, a similarity in colorant composition between both the types of cochineal is so close that it is very difficult to explicitly identify each species.

In the case of the violet thread, the same color compounds were identified (Fig. 4b). Additionally, the peak corresponding to indigotin was found in the chromatograms registered using the following detection: UV

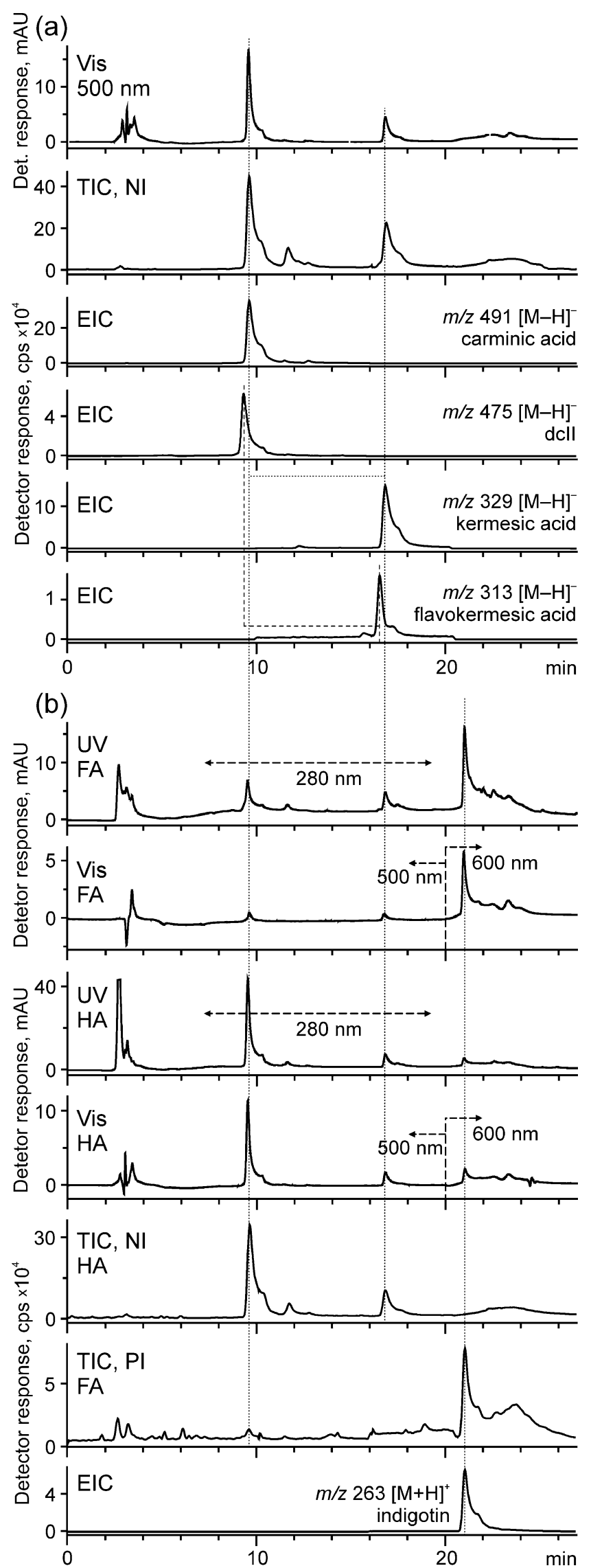


Fig. 5 Mass spectra of a carminic acid and $\mathbf{b}$ dcII (registered using orifice voltage $240 \mathrm{~V})$; on the right: selected fragmentation pathways of carminic acid (top) and dcII (bottom)

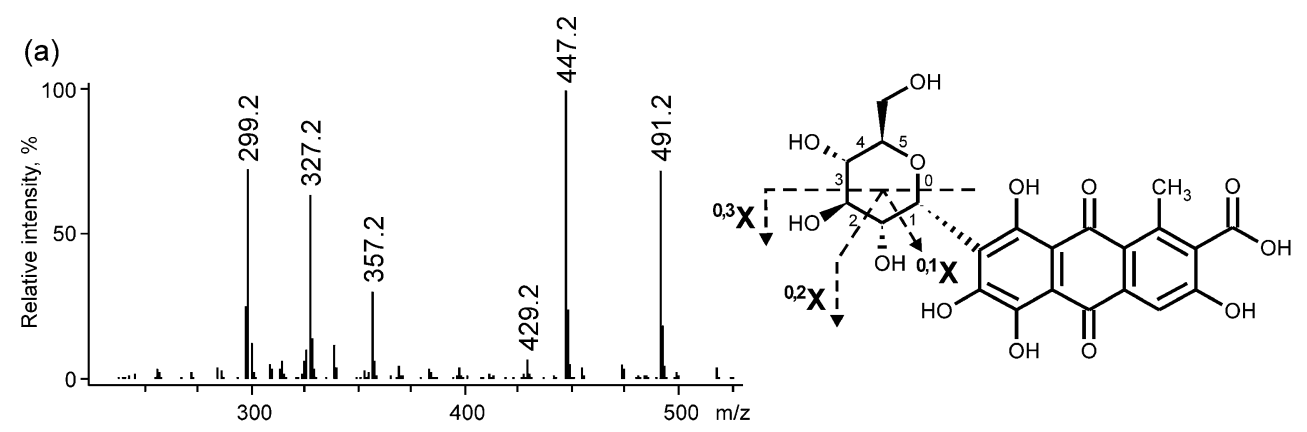

(b)

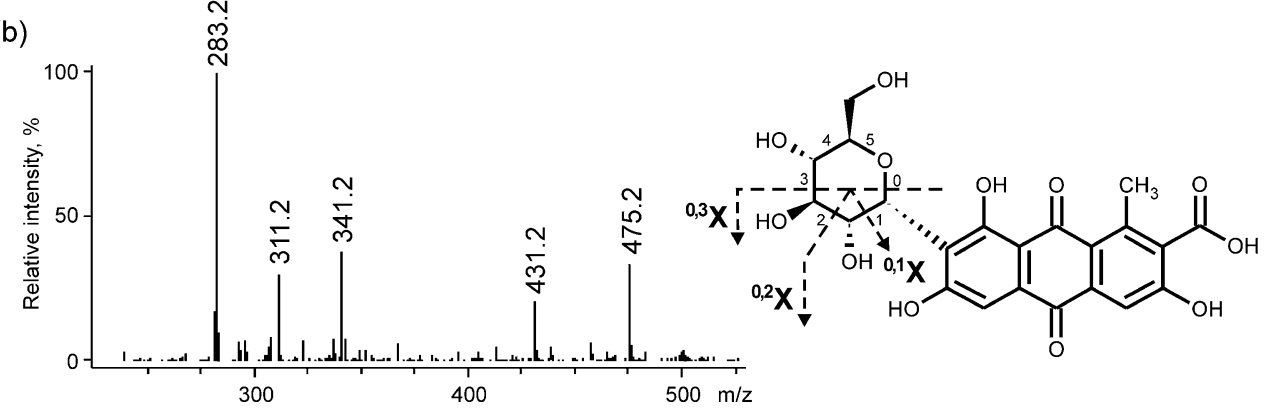

$(280 \mathrm{~nm})$, visible (600 nm), and MS (in the positive ion mode, signals at $\mathrm{m} / \mathrm{z} 263$ and 285). Moreover, small peak of isatin, which is a degradation product of indigotin, was found in the chromatograms reconstructed for the ions at $\mathrm{m} / \mathrm{z} 148$ and 170. It proved that the violet shade was obtained by dyeing of the fiber with a mixture of cochineal (probably Polish, as it can be deduced from the presence of both carminic and kermesic acids) and an unspecified indigo dyestuff.

Indigotin was also easily identified as one of the main colorant in the green fiber. The other compounds which were found in this sample, turned out to be luteolin and apigenin. When the extract with formic acid was examined, the chromatograms registered at $280 \mathrm{~nm}$ as well as PI and NI ESI MS contained two more peaks of low intensity at $10.3 \mathrm{~min}$ and $11.4 \mathrm{~min}$. Their NI mass spectra showed the signals at $\mathrm{m} / \mathrm{z} 447$ and 431 while in the positive ion mode the ions at $\mathrm{m} / \mathrm{z} 287$ and 271, which allowed suggestion that glycosides of luteolin and apigenin were isolated during the mild extraction. Their small content indicated the use of weld as a yellow dye; the green shade of the fiber was obtained by the addition of indigo or woad.

\section{Conclusions}

The examination of the protocol of the extraction of dyestuffs from textiles allowed to find that omitting of the evaporation step significantly improved the efficiency of the process. The double extraction of the same fiber, with formic acid followed by hydrochloric acid, provided more information than a one-stage procedure. The first step, the mild one, allowed isolation of glycosides, while the second one of aglycones, but with higher yield.
The developed RPLC method allows identification of 29 color compounds occurring in natural dyestuffs: from polar acids and glycoside derivatives of flavonoids and anthraquinones, through their less polar aglycones, to unpolar anthraquinones and indigoids. The optimized procedure makes the analysis considerably shorter in comparison with those recommended previously; moreover, it allows differentiation between more compounds over one analysis. The advantage of the proposed method arises from combining two detection systems, UV-Vis and ESI MS: mass spectrometric data allows identification even of nonseparated colorants thanks to differences in the registered mass-to-charge values corresponding to analyzed peaks, while spectrophotometric detection enables identification of other compounds, hardly ionizable in an electrospray MS source.

For MS detection, the selected ions monitoring mode seems to be the most efficient. Furthermore, proper identification can be performed only when chromatograms

Table 3 Fragment ions of carminic acid, dcII, dcIV, and dcVII registered for orifice voltage $240 \mathrm{~V}$

\begin{tabular}{llll}
\hline Identified ion & \multicolumn{2}{l}{ Ion $(m / z)$} \\
\cline { 2 - 4 } & Carminic acid & dcII & dcIV/dcVII \\
\hline$[\mathrm{M}-\mathrm{H}]^{-}$ & 491 & 475 & 491 \\
{$\left[\mathrm{M}-\mathrm{H}-\mathrm{CO}_{2}\right]^{-}$} & 447 & 431 & 447 \\
{$\left[\mathrm{M}-\mathrm{H}-\mathrm{CO}_{2}-\mathrm{H}_{2} \mathrm{O}\right]^{-}$} & 429 & 413 & 429 \\
{$\left[{ }^{0,3} \mathrm{X}-\mathrm{CO}_{2}\right]^{-}$} & 357 & 341 & 357 \\
{$\left[{ }^{0,2} \mathrm{X}-\mathrm{CO}_{2}\right]^{-}$} & 327 & 311 & 327 \\
{$\left[{ }^{0,1} \mathrm{X}-\mathrm{CO}_{2}\right]^{-}$} & 299 & 283 & 299 \\
\hline
\end{tabular}


are registered in both ionization modes (the negative and positive ion). The negative ion MS allows observation of most of the polar anthraquinones and flavonoids; however, non-polar indigoids need the positive ion detection.

Some colorants do not ionize in ESI MS source, e.g., hematein or hematoxylin. In their case, only spectrophotometric detection in a visible range provides information needed for identification of analyzed materials. Moreover, the registration of the chromatograms at $280 \mathrm{~nm}$ enables non-specific monitoring of a substantial number of colorants, which makes the procedure more universal as it allows identification of many more color species, not only those included in the frame of the present study.

As a consequence, the developed method based on the coupling of reversed-phase HPLC with the UV-Vis and ESI MS detection was successfully used to the identification of dyes in historical textiles of various colors. The performed studies confirmed the presence of indigotin, isatin, luteolin, and apigenin as well as carminic, kermesic and ellagic acids in the green, violet and red fibers taken from the fifteenth century chasubles from the collection of the Wawel Cathedral treasury. Apart from that, HPLC and MS investigations allowed confirming structure of dcII as 7- $\alpha$-D-glucopyranosyl flavokermesic acid. Moreover, the calculated content of carminic and kermesic acids in the red and violet fibers made it possible to specify the used dye as Polish cochineal.

Acknowledgments This research has been co-financed by the European Union from the European Social Fund as well as by the national budget, and conducted within the framework of the Integrated Operational Program of Regional Development. This work has been supported by the European Union in the framework of European Social Fund through the Warsaw University of Technology Development Programme and Center for Advanced Studies Warsaw University of Technology.

Open Access This article is distributed under the terms of the Creative Commons Attribution Noncommercial License which permits any noncommercial use, distribution, and reproduction in any medium, provided the original author(s) and source are credited.

\section{References}

1. Wouters J (1985) Stud Conserv 30:119-128

2. Wouters J, Verhecken A (1989) Stud Conserv 34:189-200

3. Novotná P, Pacáková P, Bosáková Z, Štulík K (1999) J Chromatogr A 863:235-241
4. Orska-Gawryś J, Surowiec I, Kehl J, Rejniak H (2003) J Chromatogr A 989:239-248

5. Balakina GG, Vasiliev VG, Karpova EV, Mamatyuk VI (2006) Dyes Pigm 71:54-60

6. Surowiec I, Quye A, Trojanowicz M (2006) J Chromatogr A 1112:209-217

7. Blanc R, Espejo T, López-Montes A, Torres D, Crovetto G, Navalón A, Vílchez JL (2006) J Chromatogr A 1122:105-113

8. Karapanagiotis I, Valianou L, Daniilia S, Chryssoulakis Y (2007) J Cult Herit 8:294-298

9. Vanden Berghe I, Gleba M, Mannering U (2009) J Archaeol Sci 36:1910-1921

10. Szostek B, Orska-Gawryś J, Surowiec I, Trojanowicz M (2003) J Chromatogr A 1012:179-192

11. Puchalska M, Połeć-Pawlak K, Zadrożna I, Hryszko H, Jarosz M (2004) J Mass Spectrom 39:1441-1449

12. Pawlak K, Puchalska M, Miszczak A, Rosłoniec E, Jarosz M (2006) J Mass Spectrom 41:613-622

13. Surowiec I, Szostek B, Trojanowicz M (2007) J Sep Sci 30:20702079

14. Zhang X, Good I, Laursen R (2008) J Archaeol Sci 35:1095-1103

15. Zhang X, Laursen R (2009) Int J Mass Spectrom 284:108-114

16. Marques R, Sousa MM, Oliveira MC, Melo MJ (2009) J Chromatogr A 1216:1395-1402

17. Hofenk de Graaff JH (2004) The colourful past. Origins, chemistry and identification of natural dyestuffs. Archetype, London

18. Zhang X, Laursen R (2005) Anal Chem 77:2022-2025

19. Peggie DA, Hulme AN, McNab H, Quye A (2008) Microchim Acta 162:371-380

20. Zhang X, Boytner R, Cabrera JL, Laursen R (2007) Anal Chem 79:1575-1582

21. Valianou L, Karapanagiotis I, Chryssoulakis Y (2009) Anal Bioanal Chem 395:2175-2189

22. Kostiainen R, Kauppila TJ (2009) J Chromatogr A 1216:685-699

23. Jiao Y, Zuo Y (2009) Phytochem Anal 20:272-278

24. Genovese S, Tammaro F, Menghini L, Carlucci G, Epifano F, Locatelli M (2010) Phytochem Anal 21:261-267

25. Dabiri M, Salimi S, Ghassempour A, Rassouli A, Talebi M (2005) J Sep Sci 28:387-396

26. Krupa N (2010) Włoskie tkaniny aksamitne z XV i XVI w. ze zbiorów skarbca katedry na Wawelu. Pochodzenie, styl i warsztat technologiczny (in Polish). PhD thesis, Institute of Art, Polish Academy of Sciences, Warsaw, Poland

27. Tuszyńska W (1986) Farbowanie barwnikami naturalnymi (in Polish). WARTA, Warsaw, Poland

28. Yadav LDS (2005) Organic spectroscopy. Kluwer, Dordrecht

29. Rafaëlly L, Héron S, Nowik W, Tchapla A (2008) Dyes Pigm 77:191-203

30. Petroviciu I, Albu F, Medvedovici A (2010) Microchim Acta 95:247-254

31. Peggie DA (2006) The development and application of analytical methods for the identification of dyes on historical textiles. $\mathrm{PhD}$ thesis, The University of Edinburgh, UK

32. Cardon D (2007) Natural dyes. Sources, tradition, technology and science. Archetype, London 